\title{
Persisting nutritional neuropathy amongst former war prisoners
}

\author{
*GEOFFREY V GILL, DION R BELL \\ From the Department of Tropical Medicine, Liverpool School of Tropical Medicine, Liverpool, UK
}

SUMMARY Of 898 former Far East prisoners of war, assessed between 1968 and 1981, 49 (5.5\%) had evidence of persisting symptomatic neurological disease dating back to their periods of malnutrition in captivity. The commonest syndromes were peripheral neuropathy (often of "burning foot" type), optic atrophy, and sensori-neural deafness. Though nutritional neuropathies disappeared soon after release in most ex-Far East prisoners of war, in some they have persisted up to 36 years since exposure to the nutritional insult.

The continuing health problems of former Far East prisoners of war (FEPOWs) has recently aroused much interest. ${ }^{1}$ About $20 \%$ of these men suffer persisting tropical disease, ${ }^{2}$ in particular Strongyloides stercoralis infections. ${ }^{34}$ They also have increased morbidity from other conditions such as anxiety and depression, duodenal ulcer and chronic respiratory disease. ${ }^{5}$ Some also have symptomatic nutritionallyinduced neurological syndromes (usually optic atrophy or peripheral neuropathies) present since their captivity during the war. ${ }^{2}$ We present here our detailed findings of these syndromes amongst a large group of ex-FEPOWs recently seen at the Liverpool School of Tropical Medicine. Firstly, the neurological diseases encountered during captivity will be reviewed, as they are rarely seen in modern clinical practice.

Nutritional neuropathy in the prisoner of war camps The main syndromes experienced are listed in order of frequency in table 1 . The colloquial POW names for each are included, together with a brief clinical description with references. We are indebted to the many POW medical officers who kept meticulous records under great difficulty, and recorded their experiences in the post-war medical literature,$^{7-11}$ ${ }^{15-25}$ giving us excellent records of this regrettable "natural experiment" into the neurological effects of malnutrition. The ingenuity and resourcefulness

*Present address: Department of Medicine, Baragwanath Hospital, Johannesburg 2013, South Africa.

Address for reprint requests: Dr Dion R Bell, Liverpool School of Tropical Medicine, Pembroke Place, Liverpool L3 5QA, UK.

Received 24 April 1982. Accepted 6 June 1982. of these doctors is typified by Cruickshank ${ }^{10}$ who performed a limited controlled clinical trial (intramuscular nicotinic acid versus distilled water) in men with burning feet, in Changi Jail in Singapore.

The neuropathic syndromes were undoubtedly related to malnutrition-and its ever present companion, infective disease; as they were particularly rife where food was scarce and health poor-most notably on the infamous Thai-Burma Railway. However, there is considerable disagreement amongst authors as to the exact causative nutrient of each particular syndrome (see 3rd column of table 1). Some considered that other factors such as toxins $^{21}$ or genetic predisposition ${ }^{22}$ may be operative-especially in relation to nutritional ambylopia. In addition, it was noted that the response to vitamin therapy was frequently disappointing. ${ }^{27}$

Many FEPOWs suffered several neuropathic syndromes at the same time (see later case histories) in particular peripheral neuropathy and amblyopia frequently co-existed. This led some to think of the FEPOW neuropathies as part of a syndrome..$^{25}$ This is supported by various reports of remarkably similar neurological conditions occurring in various times and places around the world, ${ }^{128-31}$ always affecting subjects with poor nutrition. These reports are summarised in table 2, and attention is particularly drawn to the quoted description by Henry Strachan in $1897^{28}$ of his observations on native West Indians; the similarity with the FEPOW syndrome is very striking. Not surprisingly, it has been suggested that the neuropathic diseases suffered by the FEPOWs be termed "Strachan's Disease." 32 
Table 1 Syndromes of nutritional neuropathy seen in prisoner of war camps

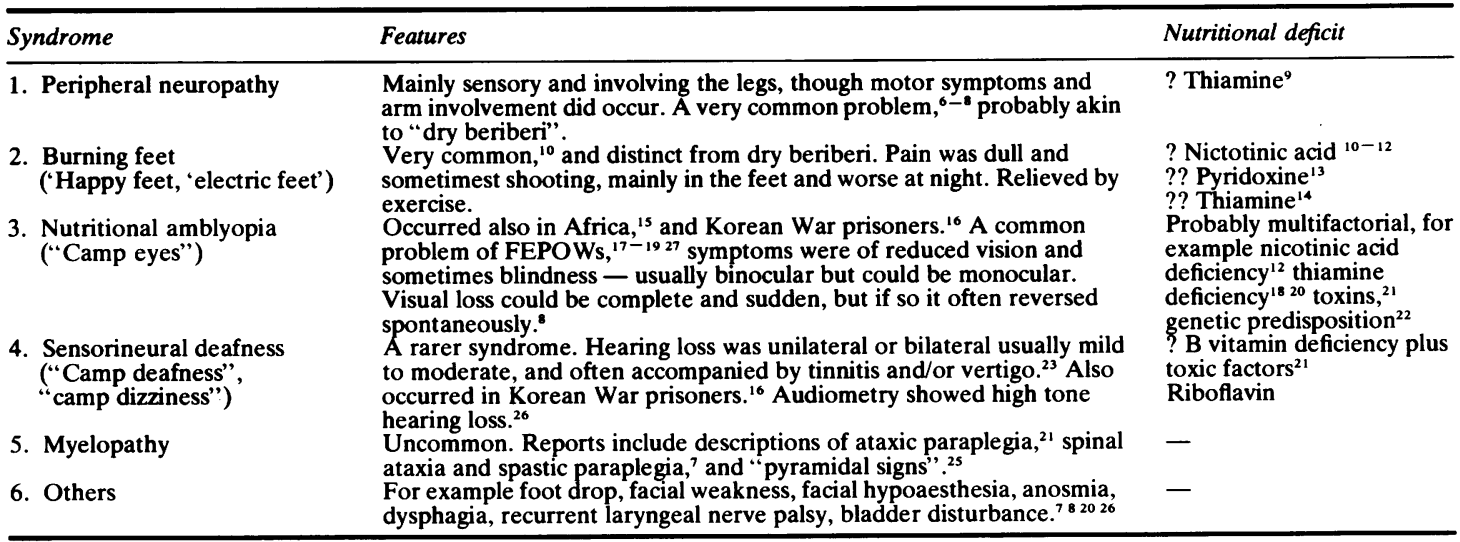

Table 2 Other reports of FEPOW-type neuropathic disease (? Strachan's Disease)

\begin{tabular}{|c|c|c|c|}
\hline Date & Author & Population & Description \\
\hline 1. 1897 & Strachan $^{28}$ & West Indian natives & $\begin{array}{l}\text { ". numbness and cramps in his hands ... dimness of sight ... hard } \\
\text { of hearing ... suffers from severe burning in the palms of the hands } \\
\text { and soles of the feet, and very often this is worse at night } \ldots \text { and } \\
\text { prevents his resting." }\end{array}$ \\
\hline 2. 1911 & Stannus $^{12}$ & $\begin{array}{l}\text { Inmates of Zomba Jail } \\
\text { Nyasaland (Malawi) }\end{array}$ & "burning pains in the soles of the feet" \\
\hline 3. 1929 & Sharples ${ }^{29}$ & $\begin{array}{l}\text { Sugar plantation } \\
\text { labourers in British } \\
\text { Guiana }\end{array}$ & "footburning", \\
\hline 4. 1940 & Pallister ${ }^{30}$ & $\begin{array}{l}\text { Chinese immigrants to } \\
\text { Malaya }\end{array}$ & $\begin{array}{l}\text { Ataxia, paraesthesiae, reduced vibration sense, burning feet and weak- } \\
\text { ness of the legs. Possibly related to eating polished rice. Response to } \\
\text { vitamin therapy poor. }\end{array}$ \\
\hline 5. 1945 & Spillane and Scott ${ }^{31}$ & $\begin{array}{l}\text { German prisoners of } \\
\text { war in Middle East }\end{array}$ & $\begin{array}{l}\text { "Obscure neuropathy" consisting of various combinations of optic } \\
\text { atrophy, tinnitus, nerve deafness, ataxia, paraesthesiae and paraplegia. } \\
\text { Occurred when nutrition was poor and dysentery rife. Vitamin treat- } \\
\text { ment unhelpful. }\end{array}$ \\
\hline
\end{tabular}

The aetiology would seem most likely to be multiple B vitamin deficiency, with possibly environmental toxic factors being also necessary.

\section{Patients and methods}

Between January 1968 and December 1981 inclusive, 898 former FEPOWs were seen at the Liverpool School of Tropical Medicine. The men came mainly from the North of England, and all had been imprisoned in the Far East for a $3 \frac{11}{2}$ year period from 1942 to 1945 . They were therefore examined between 23 and 36 years after release, the mean period being 32 years. At the time of assessment most men were in their late fifties or early sixties. All were admitted for a period of about one week, and underwent clinical evaluation and intensive investigation to exclude tropical disease and assess general health.

Case notes were analysed retrospectively, and those with persisting nutritional neuropathies were divided into two groups. (1) "Definite" These men gave good histories of nutritional neuropathy whilst FEPOWs, and symptoms had persisted (though usually reduced in intensity) up to presentation. They also had supportive abnormal physical signs on examination, and many had investigations (for example perimetry, audiometry, nerve conduction studies, visual evoked responses etc) also supporting the diagnosis. (2) "Possible" These ex-FEPOWs had histories of nutritional neuropathy whilst imprisoned, but their symptoms had resolved completely before or soon after repatriation. However, when seen at Liverpool, they had abnormal physical signs thought likely to be due to their previous neurological syndromes. Further investigations were not performed on these patients. In both groups, patients with diabetes mellitus, cervical or lumbar spondylosis, alcoholism, disseminated sclerosis, cerebrovascular disease or any other condition that could possibly cause similar neurological abnormalities, were excluded. In addition, details of patients in the "possible" group were examined by an independent consultant neurologist, and patients were excluded whose signs were considered to be of dubious significance, especially in relation to age.

\section{Results and Case Histories}

The results are summarised in table 3 . Forty-nine of the 898 ex-FEPOWs $(5 \cdot 5 \%)$ were considered to be suffering from persisting nutritional neuropathy, with a further $38(4.2 \%)$ having possible signs of asymptomatic nutritional neurological damage. 
Table 3 Nutritional neuropathy amongst 898 ex-FEPOWs assessed 23 to 36 years after captivity

\begin{tabular}{lr} 
A. "Definite" (symptomatic) neurological disease \\
1. Peripheral neuropathy & 24 \\
2. Optic atrophy & 19 \\
3. Sensorineural deafness & 13 \\
4. Myelopathy & 2 \\
\hline & TOTAL of 58 conditions amongst 49 ex-FEPOWs \\
& (prevalence of 5.5\%)
\end{tabular}

A. "Definite" (symptomatic) neurological disease (prevalence of $5 \cdot 5 \%$ )
B. "Possible" (asymptomatic) neurological disease

1. Impaired tendon reflexes

2. Impaired sensation

3. Optic atrophy

4. Fasciculation

5. Wasting and weakness

6. Spastic monoparesis

TOTAL of 42 abnormalities amongst 38 ex-FEPOWs (prevalence of $4 \cdot 2 \%$ )
Interestingly, in the "definite" group, the syndromes encountered and their relative frequency were similar to the pattern during imprisonment (see table 1). The findings in this group will be considered in detail, with illustrative case histories.

1. PERIPHERAL NEUROPATHY

Twenty-four ex-FEPOWs fell into this group, 11 of whom had persisting "burning feet" syndromes. Other symptoms were usually of paraesthesiae or weakness. Of the 24 patients, the neuropathy was mainly sensory in eight, mainly motor in six, and mixed in 10 . The arms were rarely affected.

Case 1 This 62-year-old-man was assessed 35 years after release, in 1980 . He was interned in Java and the Celebes where he suffered malaria, dysentery, wet beriberi and paraesthesiae of the legs with loss of sensation of ground contact. His vision was also blurred. He regained good health on release, but paraesthesiae of his feet continued. When examined at Liverpool he had reduced pain and temperature sensation bilaterally, to mid-thigh level. Nerve conduction studies confirmed a "patchy peripheral nerve lesion consistent with nutritional neuropathy".

Case 2 A 57-year-old ex-FEPOW was seen in 1975. He had been interned in Rangoon during the war, had suffered chronic dysentery, and lost $32 \mathrm{~kg}$ in weight. He developed paraesthesiae peripherally, burning of the hands and legs, unsteadiness in the dark, deafness and poor vision. After the war his symptoms gradually improved, but paraesthesiae, unsteadiness and burning feet persisted. He was regularly kept awake at night by the pains in his feet, and he would walk around the house to gain relief. Examination revealed marked signs of a sensory neuropathy in the legs, as well as evidence of posterior column loss.

\section{OPTIC ATROPHY}

Nineteen ex-FEPOWs had reduced visual acuity due to old nutritional amblyopia. Many were quite severely affected and some were on the blind register. The physical signs were of disc pallor, reduced acuity and sometimes field defects.

Case 3 A prisoner of war captured in the Java Sea spent his captivity in the Celebes, where he suffered recurrent malaria, wet beriberi, and for a period of 3 months was completely blind. His sight returned, but vision remained poor. When seen in Liverpool in 1978 (at age 61 years and 33 years after release) a consultant ophthalmologist found pale discs, 6/18 vision with refraction bilaterally, central and paracentral scotomata in both eyes, and complete absence of colour vision.

Case 4 A 65-year-old ex-FEPOW was seen in 1980. He complained of poor vision since the war, and an opthalmologist reported bilateral temporal disc pallor, $6 / 9$ vision on the right and $6 / 60$ on the left (with refraction). Visual evoked responses showed abnormally formed low amplitude patterns, with significant delay from both eyes, especially the left.

\section{SENSORINEURAL DEAFNESS}

Thirteen cases were found, three being unilateral and the rest bilateral. Most cases were mild or moderate in severity, and tinnitus and vertigo were common accompaniments. Audiometric findings were of high tone loss, as with other reported cases. $^{26}$ For this reason ex-POWs with a significant history of noise exposure were excluded from consideration for this group.

Case 5 A soldier was captured in Singapore, and worked on the Thai-Burma Railway for the rest of his captivity. He suffered many attacks of malaria and dysentery, severe wet beriberi, paraesthesiae of the hands and legs, burning feet, poor vision, deafness, ataxia and weakness of the legs. His neurological symptoms had reduced but persisted since release. When assessed in 1976, at the age of 58 years, he had signs of a mixed peripheral neuropathy of the legs, optic atrophy and bilateral sensorineural 
deafness. Audiometry revealed high-tone hearing loss in both ears. A hearing aid was of little benefit.

4. MYELOPATHY

Two patients had features of spinal cord disease, one with posterior column symptoms and signs (Case 2), and the other with a spastic paraparesis.

Case 6 An ex-FEPOW reported that he had developed weakness of both legs and poor vision whilst in captivity. Though less severe, these symptoms had persisted after repatriation, and he also noticed stiffness of his legs. He was assessed in Liverpool in 1968, when signs of a spastic paraparesis, worse on the left, as well as mild optic atrophy were discovered.

\section{Discussion}

The important finding of this study is that former POWs in Britain today may still suffer neurological syndromes related to their malnutrition in captivity. Of our large series of 898 men, $5.5 \%$ were affected up to 36 years later. Some previous studies have recorded similar nutritional neuropathy amongst ex-FEPOWs, but not in great detail nor over such a long period since release. In Canada, optic atrophy and peripheral neuropathy were recorded 8 years, ${ }^{33}$ 12 years, ${ }^{34}$ and 20 years ${ }^{35}$ after repatriation, with some suggestion that recovery (partial or complete) occurred in some during the early post-war years. ${ }^{33}$ Our results, however, show that a substantial minority still have neurological deficit up to 36 years after return to a normal diet, and it would seem likely that in most of these men the effects will be permanent. This is perhaps not surprising, as necropsy studies on ex-FEPOWs who died soon after the war showed extensive degeneration and demyelination in areas such as the posterior columns or VIII cranial nerve, ${ }^{1132}$ generally correlating with the clinical deficit in life.

In Britain, many ex-FEPOWs were medically assessed at Queen Mary's Hospital, Roehampton. ${ }^{26}{ }^{36}$ Some 4,684 men were seen since 1945 and $679(14.5 \%)$ were reported to have optic atrophy or peripheral neuropathy. ${ }^{26} 36$ This group were not studied in great detail, and the high prevalence compared to our figure of $5.5 \%$ is probably mainly because the group contains many ex-FEPOWs assessed much sooner after repatriation than our own.

Interestingly, analysis of the Roehampton group of ex-POWs has revealed a high prevalence of other neurological diseases-notably Parkinsonism and spinal cord syndromes with an onset many years after release from captivity. ${ }^{36}$ It has been suggested that these late syndromes may result from slow arbovirus infection, originally acquired in the Far East. ${ }^{37}$ We have not specifically looked for such late neurological disease but we have seen ex-FEPOWs with signs of early dementia, as has also been reported from Roehampton ${ }^{36}$ (one patient from the latter group had cortical atrophy confirmed by pneumo-encephalography ${ }^{26}$ ). Although it is difficult to be certain of a relationship with malnutrition in these cases, it is interesting that Norwegian workers have reported organic cerebral damage (including confirmed cortical atrophy) in a group of survivors from German concentration camps. ${ }^{38}$ Of further interest, all the patients in the Norwegian study had psychiatric syndromes. These, too, are common amongst British ex-FEPOWs ${ }^{5}$ (about one-third have overt and disabling anxiety or depression or both). Could we be observing here a nutritionally induced combined neuropsychiatric syndrome ${ }^{1}$ ?

Many thousands of former FEPOWs are still alive, and are at an age when they may be presenting to physicians with a variety of acute and chronic medical conditions. It is important that doctors are aware of the special health problems of this unfortunate group of men, and to these must be added persisting nutritional neuropathic disease.

\section{References}

' Leading article. The health of former Far-East prisoners of war. Lancet 1980;2:132-3.

${ }^{2}$ Gill GV, Bell DR. Persisting tropical diseases amongst former prisoners of war of the Japanese. Practitioner 1980;224:801-3.

${ }^{3}$ Gill GV, Bell, DR. Strongyoides stercoralis infection in former Far East prisoners of war. $\mathrm{Br} \mathrm{Med} J$ 1979;2:572-4.

${ }^{4}$ Grove DI. Strongyloidiasis in allied ex-prisoners of war in South-East Asia. Br Med J. 1980;1:598-601.

${ }^{5}$ Gill GV, Bell DR. The health of former prisoners of war of the Japanese. Practitioner 1981;225:531-8.

- Brill NQ. Neuropsychiatric examination of military personnel recovered from Japanese prison camps. Bull US Med Dept. 1946;5:429-38.

${ }^{7}$ Denny-Brown D. Neurological conditions resulting from prolonged and severe dietary restriction. Medicine 1947;26:41-113.

${ }^{8}$ Smith DA, Woodruff MFA. Deficiency diseases in Japanese prison camps. MRC Special Report Series 1951; No. 274.

${ }^{9}$ Burgess RC. Deficiency diseases in prisoners of war at Changi, Singapore. Lancet 1946;2:411-8.

${ }^{10}$ Cruickshank EK. Painful feet in prisoners of war of the Far East. Lancet 1946;2:368-72.

${ }^{11}$ Crawford JN, Reid JAG. Nutritional disease affecting Canadian troops held prisoner of war by the Japanese. Canad J Res 1947;25E:53-85.

12 Stannus HS. Pellagra in Nyasaland. Trans $R$ Soc Trop Med Hyg 1911;5:112-19. 
${ }^{13}$ Vilter RW, Mueller JF, Glaser HS et al. The effect of vitamin B6 deficiency induced by desoxypyridoxine in human beings. $J$ Lab Clin Med 1953;42:335-57.

${ }^{14}$ Bozzetti F. Long term parenteral nutrition. Br Med J 1979;1:487-8.

${ }^{15}$ Moore DF. Nutritional retrobulbar neuritis. Lancet 1946;2:246-8.

${ }^{16}$ King JH, Passmore JW Nutritional amblyopia-a study of American prisoners of war in Korea. $\mathrm{Am} \mathrm{J} \mathrm{Oph-}$ thalmol 1955;39:173-86.

${ }^{17}$ Ridley HR. Ocular manifestations of malnutrition in released prisoners of war from Thailand. $\mathrm{Br} J \mathrm{Oph}$ thalmol 1945;29:613-8.

${ }^{18}$ Bloom SM, Merz EH, Taylor WN Nutritional amblyopia in American prisoners of war liberated from the Japanese. Am J Ophthalmol 1946;29:1248-57.

${ }^{19}$ Bell PG, O'Neill JC. Optic atrophy in Hong Kong prisoners of war. Canad Med Assoc J 1947;56:475-81.

${ }^{20}$ Lang WR. Vitamin B deficiency in ex-prisoners of war from Japan. NZ Med J 1946;45:296-307.

${ }^{21}$ Clarke CA, Sneddon IB. Nutritional neuropathy in prisoners of war and internees from Hong Kong. Lancet 1946;1:734-7.

${ }^{22}$ Dekking HM. Tropical Nutritional amblyopia ("camp eyes"). Ophthalmologica 1947;113:65-92.

${ }^{23}$ Hobbs HE, Forbes FA. Visual defects in prisoners of war. Lancet 1946;2:149-53.

${ }^{24}$ O' Regan JAR. Prisoners of war from Singapore-a medical report. NZ Med J 1945;44:329-34.

${ }^{25}$ Garland HC. Ocular signs in the prisoner of war from the Far East. Br Med J 1946;1:143.

${ }^{26}$ Walters JH, Caplan JP, Hayward EW. A FEPOW Survey. Report to DHSS from Queen Mary's Hospital,
Roehampton, 1971 (DHSS Norcross Library, Blackpool, UK).

${ }^{27}$ Lian SB. Camp amblyopia. Ophthalmologica 1947;113:38-44.

${ }^{28}$ Strachan $\mathrm{H}$. On a form of multiple neuritis prevalent in the West Indies. Practitioner 1897;59:477-84.

${ }^{29}$ Sharples LR. The condition of "burning feet" or "footburning" in labourers on sugar plantations in the Corentyne District of British Guiana.J Trop Med Hyg 1929;32:258-360.

${ }^{30}$ Pallister RA. Ataxic paraplegia occurring amongst Chinese in Malaya. Trans $R$ Soc Trop Med Hyg 1940;34:203-11.

${ }^{31}$ Spillane JD, Scott GI. Obscure neuropathy in the Middle East. Lancet 1945;2:261-4.

${ }^{32}$ Fisher M. Residual neuropathological changes in Canadians held prisoner of war by the Japanese. Canadian Service Medical Journal 1955;11:157-99.

${ }^{33}$ Adamson JD, Judge CM. Residual disability in Hong Kong prisoners of war. Can Scrv Med J 1956;12:837-56.

${ }^{34}$ Coke LR. Late effects of starvation. Can Serv Med J 1961;17:313-24.

${ }^{35}$ Kral VA, Pazder LH, Wigdor BT. Long term effects of prolonged stress experience. Can Psych Ass J 1967;12:175-81.

${ }^{36}$ Gibberd FB, Simmonds JP. Neurological disease in ex-Far East prisoners of war. Lancet 1980;2:135-7.

${ }^{37}$ Sutton RNP. Neurological disease in former Far East prisoners of war. Lancet 1980;2:263-4.

${ }^{38}$ Strom A, Refsum SB, Eutubger L et al. Examination of Norwegian ex-concentration camp prisoners. $J$ Neuropsychiatry 1962;4:43-62. 